\title{
Racismo e representatividade da criança negra na literatura infantil: reflexões sobre o projeto de extensão e cultura "CONSTRUINDO A PRÓPRIA HISTÓRIA"
}

Resumo: Os livros, "Eu posso ser... o que eu quiser ser" e "Clube da Alegria', são frutos do projeto de extensão, CONSTRUINDO A PRÓPRIA HISTÓRIA: racismo e representatividade da criança negra na literatura infantil, com fomento do edital Programa de Bolsas de Apoio à Cultura e à Arte - PROCARTE, cujo número do registro é 026.2.035-2017. O primeiro livro indicado, conta a história de uma criança negra que desejava ser princesa, mas que diante da imagem e comportamentos idealizados dessa figura, historicamente carregada de estereótipos, se angustia ao perceber que o seu sonho não "cabe" no mito. A história foi idealizada para ser trabalhada em uma escola de educação infantil, nesse caso, o CMEl da Bela Vista, localizada em um bairro periférico da cidade de Diamantina. A história foi apresentada e contada para as crianças de cinco anos desta instituição, que a partir dos questionamentos feitos pela personagem principal do livro, foram instigadas a construírem a sua própria história.

Palavras-chave: Representatividade. Literatura Infantil. Racismo

\section{Racism and representativeness of the black child in children's literature: reflections on the project of extension and culture "BUILDIND ONE'S OWN HISTORY"}

\begin{abstract}
The books, "Eu posso ser ... o que eu quiser ser" and "Clube da Alegria," are the fruits of the extension project, BUILDING ONE'S OWN HISTORY: racism and representativeness of the black child in children's literature, with the promotion of the Program of Scholarships to Support Culture and Art - PROCARTE, whose registration number is 026.2.035-2017. The first book, tells the story of a black child who wanted to be a princess, but who in the face of the image and idealized behaviors of this figure, historically charged with stereotypes, is distressed to realize that his dream does not "fit" into the myth. The story was designed to be worked in a school of early childhood education, in this case, the CMEl of Bela Vista, located in a peripheral district of the city of Diamantina. The story was presented and told to the children of the five years of this institution, who, based on the questions asked by the main character of the book, were instigated to build their own story.
\end{abstract}

Keywords: Representativeness. Children's literature. Racism.

'Doutora em Sociologia UNESP/Campus Araraquara-SP; Programa Mestrado (Profissional) em Educação da Universidade Federal dos Vales do Jequitinhonha e Mucuri. Email:geruzaft@hotmail.com

${ }^{2}$ Gerente do Ensino Fundamental da cidade de Diamantina-MG; Mestre em Educação Universidade Federal dos Vales do Jequitinhonha e Mucuri. E-mail: Iugoncalves1000@gmail.com

${ }^{3}$ Discente Sistemas de Informação Universidade Federal dos Vales do Jequitinhonha e Mucuri. E-mail: davidsonbruno@outlook.com 


\section{Introdução}

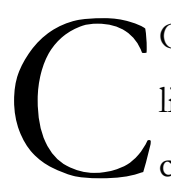

ONSTRUINDO A PRÓPRIA HISTÓRIA: racismo e representatividade da criança negra na literatura infantil, foi um projeto de extensão submetido e aprovado no edital sobre arte e cultura - PROCARTE da Universidade Federal dos Vales do Jequitinhonha e Mucuri-UFVJM, no ano de 2017, cujo número do registro é 026.2.035-2017. O projeto contou com o apoio de um designe, estudante da UNIBH, criador gráfico dos principais personagens e da diagramação do primeiro livro, "Eu posso ser ...o que eu quiser ser!", um bolsista do curso de Sistemas de Informação da UFVJM, responsável pela arte e diagramação final do primeiro livro, e especialmente, do segundo livro, "Clube da Alegria", uma docente especialista em literatura, membro do Programa de Mestrado em Educação da UFVJM - PPGEd, uma discente, mestranda em educação, e outros dois discentes de Sistemas de Informação que atuaram como colaboradores no projeto. Um desses últimos discentes citados, desenvolveu o site para a divulgação e obtenção gratuita dos livros infantis, cujo endereço é: https://construindoapropriahistoria.teios.org/. O projeto teve como principal finalidade trabalhar com questões relacionadas ao racismo na infância, em um Centro Municipal de Educação Infantil - CMEI, localizado em um bairro periférico da cidade de Diamantina, Minas Gerais, o bairro Bela Vista, por meio de uma obra literária cuja narrativa foi construída pela coordenadora do projeto. A implantação do projeto no CMEI, que contou com duas turmas, num total de 50 crianças, obteve respaldo irrestrito da equipe pedagógica, da gestão da escola e da Secretaria Municipal de Educação da cidade de Diamantina.

A narrativa do primeiro livro "Eu posso ser... o que eu quiser ser!", texto base que serviu de ponto de partida para o trabalho no CMEI, explicita as aflições e questionamentos da protagonista, Eduarda, uma menina negra de cinco anos de idade, que sonhava em ser princesa. A proposta era que as crianças do CMEI, depois de ouvirem e conversarem sobre a história, pudessem iniciar reflexões sobre o assunto que, absorvidas ao longo do processo pelas práticas pedagógicas, contribuiriam para o desenvolvimento de um novo olhar das relações familiares e sociais, ampliando suas expectativas e sonhos, viabilizando questionamentos sobre os "lugares" naturalizados, definidos pela cor da pele e/ou classe social. A expectativa era contribuir para que as crianças, ao final do processo, ao experimentarem o desafio de protagonizarem as suas próprias histórias e fantasias, por meio de seus desenhos e narrativas, fossem capazes de desejar outras e novas histórias para as suas vidas, muito mais ampliadas. Assim, a narrativa do segundo livro "Clube da alegria", foi elaborada a partir da vida e das histórias contadas pelas crianças, por meio de seus desenhos, dando continuidade ao primeiro livro.

Como afirmado anteriormente, o primeiro livro conta a história de uma criança negra que desejava ser princesa, mas que diante da imagem e comportamento idealizados dessa figura, historicamente carregada de estereótipos, se angustia ao perceber que o seu sonho não "cabe" no mito. Dessa forma, inicia-se uma tentativa de ressignificar o conceito de princesa introjetado violentamente pelas relações sociais historicamente estabelecidas, especificamente no Brasil, no imaginário infantil. A 
narrativa, que se preocupa em manter a pureza do encantamento, do lúdico e da inocência, não se eximiu de explicitar uma das etapas mais difíceis da vida de uma pessoa de pele negra, a infância, especialmente às mulheres, na qual lhes são apresentadas, na maioria das vezes de forma cruel, o que é "ser negro" no Brasil.

Neste contexto de dor e ansiedade gerado pelo preconceito e pela falta de representatividade positiva dos negros na literatura, especificamente nos clássicos infantis, que se transformam em desenhos televisionados, e viram fenômenos de vendas, vorazmente patrocinados pela mídia de massa, e consumidos em formas de brinquedos, roupas, sapatos, temas de festas de aniversários, tal como as princesas da Disney, está claro que a criança negra não se identifica, não se reconhece e, portanto, não deseja ter as características da sua etnia. Porém, ao longo da história, nesse primeiro livro, diante da constatação, estimulada por uma circunstância dialógica em família, de que a diferença é imanente à natureza humana, a personagem do livro se posiciona a favor dessa singularidade, valorizando-a, reconhecendo o valor das diferenças no mundo.

Com um texto simples e direto, o primeiro livro pretendeu demonstrar como os questionamentos infantis são momentos oportunos e extremamente ricos para o processo de formação e amadurecimento sadio da criança, minimizando traumas que possam surgir em decorrência de um ambiente em que o racismo e o preconceito estão naturalizados.

Compartilhar essa história nas escolas do ensino infantil, especialmente no CMEI da Bela Vista, proporcionou uma circunstância dialógica, na qual as crianças, especialmente as de pele negra, puderam se identificar com os conflitos da personagem e também se posicionarem a favor do diverso, da liberdade de escolha sobre as cores, sobre o que vestir, sobre o que e como brincar, e da possibilidade de estabelecerem, dentro de parâmetros éticos, um comportamento solidário, no qual as histórias da própria vida não devem se mirar em padrões predefinidos e estereotipados, porque estas vidas e suas subjetividades devem ser livremente construídas.

O primeiro contato que as crianças tiveram com o texto, foi por meio do livro digital, hospedado em um site no qual uma bolsista, do curso de Sistemas de Informação, cuja bolsa foi adquirida com recursos do programa da Assistência Estudantil da UFVJM, desenvolveu uma página específica para o livro https://construindoapropr HYPERLINK

"https://construindoapropriahistoria.teios.org/"iahistoria.teios.org/. Para que a leitura do mesmo fosse realizada pela equipe do projeto para as duas turmas de crianças do CMEI, as mesmas foram unidas numa sala ampla utilizada, normalmente, como refeitório. A sala foi preparada para que o livro digital fosse projetado em uma tela, tal qual um cinema. A medida que a leitura das páginas ia ocorrendo, contada no microfone pela colaboradora, mestranda em educação, servidora da Secretaria Municipal de Educação e especialista em contos infantis, as crianças fixavam os olhos nas imagens projetadas. Antes porém, foi criado um clima lúdico, no qual as crianças aprenderam a cantar a música da "Princesa Eduarda", escrita pela mestranda, especialmente para o livro. 


\section{Racismo e literatura infantil: um caminho necessário}

Sendo a literatura uma forma de expressão, entre as suas características estão a de tornar a realidade social compreensível de acordo com determinada concepção de mundo. Articula a subjetividade do autor, que deseja se comunicar, com a lógica da estrutura gramatical, na qual a fantasia ou a ficção, estão condicionadas à dinâmica estruturada pela linguagem.

Por isso, a literatura não deixa de ser realista, documentando seu tempo de modo lúcido e crítico; mas revela-se sempre original, não esgotando as possibilidades de criar, pois o imaginário empurra o artista à geração de formas e expressões inusitadas (ZILBERMAN, 2009, p. 17).

A autora indica que, a experiência da leitura de um texto literário, teria a capacidade de provocar no indivíduo os efeitos do estado de alteridade, capaz de expandir os horizontes daquele que lê, mesmo em situações em que o contexto vivido é completamente diferente do lido. Além disso, o leitor também é provocado a compartilhar as experiências de leitura, debater pontos de vistas e concepções sobre o texto,

Em certa medida, a leitura sugere outra faceta educativa da literatura: o texto artístico talvez não ensine nada, nem queira fazê-lo; mas seu consumo induz a práticas socializantes, que, estimuladas, mostram-se democráticas, porque igualitárias (ZILBERMAN, 2009, p.18).

A literatura infantil é um gênero mais abrangente do que a literatura, restrita somente aos adultos e, por isso mesmo, enquanto literatura, deve ser "mensagem de arte, beleza e emoção" (MARCHENS Apud RODRIGUES E AQUINO, 2010, p.2). Ainda segundo o autor, por meio da literatura infantil é possível identificar dramas e conflitos sociais de um determinado momento histórico e, no Brasil, especialmente durante a ditadura militar, foi possível encontrar uma brecha cultural neste gênero para que as ideologias mais progressistas, humanizadoras, denominadas de esquerda pudessem ser disseminadas.

Por isto é de fundamental importância não reduzir a literatura infantil apenas ao processo de instrumentalização pedagógica, a reconhecendo também, como um legado histórico, político e social fundamental, que fará parte do imaginário dos futuros adultos.

De acordo com Rodrigues e Aquino (2010, p. 2), para compreender a relação entre o racismo e a literatura infantil recorre-se a necessidade socialmente e historicamente construída, especialmente após o século XV, no momento de expansão marítima e de conquista de outros povos, de classificar as pessoas e a partir disso compreender a diversidade humana com traços e características morfológicas visivelmente diferentes. Nesse caso, “[...] o contato com o outro, sobretudo um outro de costumes, língua e crenças diferentes, gerou a necessidade de explicações forjadas a princípio pela Teologia e, posteriormente pela Ciência. [...]” (RODRIGUES E AQUINO, 2010, p. 2).

Ao buscar compreender a complexidade do racismo na sociedade brasileira, negado publicamente, mas praticado em situações privadas, a autora Schwarcs (2012) em sua obra "Nem Preto, Nem Branco, Muito Pelo Contrário", menciona um livro de "Contos para crianças" publicado no Brasil em 1912, que traz histórias cujo tema principal se trata do desejo de branqueamento por parte das pessoas negras. 
Detalha, especificamente, a história da "Princesa Negrina", uma criança negra, filha de um casal da realeza, fruto resultante de um comovente pedido à fada madrinha, já que o casal, naturalmente, não poderia ter filhos. Como recompensa por serem muito bondosos, mas, visto que nem tudo era perfeito, a criança, mesmo bela, nasceu "terrivelmente preta" segundo os serviçais do rei (SCHWARCS, 2012, p. 10). No entanto, a sina da criança poderia ser revertida, desde que esta fosse mantida no castelo até completar 16 anos de idade. A questão é que, como em todo conto de fada, a já adolescente foi tentada por uma serpente a sair de casa, sendo amaldiçoada para sempre a ficar preta. Desamparada, concordou em se casar com uma espécie de monstro que, com o passar do tempo, se revelou ser digno do seu amor. Ao descobrirem o verdadeiro amor um pelo outro, se transformaram mutuamente, ele em um belo e branco Príncipe Diamante e ela, em uma linda princesa branca (SCHWARCS, 2012, p. 11).

Em outra obra da autora, ao revelar o tema central desses contos para crianças, explicita um período histórico fundamental para se compreender como o Brasil construiu uma interpretação sobre si mesmo, questionando que tipo de povo deveria servir ao futuro de uma nação evoluída. Assim, a partir da década de setenta, do século XIX, o Brasil vivenciava o início do fim da escravidão, mais especificamente com a Lei do Ventre Livre (1871), e por isso, respaldou o seu projeto de nação e civilidade, em teorias liberais, positivistas/evolucionistas e racistas que cumpriram papel fundamental nas relações sociais brasileiras. Sobre este contexto afirma,

Paradoxo interessante, liberalismo e racismo corporificaram, nesse momento, dois grandes modelos teóricos e explicativos de sucesso local equivalente e, no momento contraditório: o primeiro fundamentava-se no indivíduo e em sua responsabilidade pessoal; o segundo retirava a atenção colocada no sujeito para centra-la na atuação do grupo entendido enquanto resultado de uma estrutura biológica singular (SCHWARCS, 1993, p.20-21).

As teorias raciais do século XIX, também conhecidas como pseudociências, que no contexto europeu passavam por um crivo crítico teórico intensivo, foram absorvidas pela sociedade brasileira, sem essa devida consideração. De acordo com a autora, o determinismo de tais modelos, do ponto de vista do conteúdo, foi utilizado de maneira "caricatural" em território brasileiro. Assim, no contexto social, político e econômico dessa época, "as teorias raciais se apresentavam enquanto modelo teórico viável na justificação do complicado jogo de interesses que se montava" (SCHWARCS, 1993, p. 24). Era necessário pensar que para manter a estrutura hierárquica rígida de poder de uma determinada classe brasileira e a substituição da mão de obra escrava, seria imprescindível "estabelecer critérios diferenciados de cidadania" (SCHWARCS, 1993, p. 24).

Dessa forma, os modelos teóricos que justificavam o "atraso brasileiro", especialmente em relação aos países considerados mais desenvolvidos, notadamente a Europa, também explicavam as formas de inferioridade socioeconômica existente, de "negros africanos, trabalhadores, escravos e ex escravos", consideradas ao todo "classes perigosas" (SCHWARCS, 1993, p. 38).

Assim, apoiada em autores que analisam essa época, e ao considerar o período de meados do século XIX a fase das "especializações, das grandes sínteses" que vão da termodinâmica a teoria da 
evolução, apresenta um resumo, a partir de vários autores brasileiros, das explicações fundamentadas em modelos teóricos que inviabilizavam a existência do Brasil como uma nação desenvolvida e civilizada.

Assim, se não se pode afirmar a existência de um consenso no que se refere a representação do país no exterior, é necessário destacar a força e a relevância desse tipo de interpretação pessimista, que via no Brasil um 'modelo de falta e atraso' em função de sua composição étnico e racial (SCHWARCS, 1993, p. 48).

Na obra já citada, "Nem Preto, Nem Branco, Muito Pelo Contrário", no trecho dedicado as histórias sobre a miscigenação, fica claro como a literatura, juntamente com as publicações científicas e jurídicas da época, questionavam a capacidade civilizatória do povo brasileiro, extremamente miscigenado e, portanto, desde o I Congresso Internacional das Raças, realizado em 1911, defendia-se o processo de branqueamento do Brasil.

[...] o antropólogo Roquete Pinto, como presidente do I Congresso Brasileiro de Eugenia, que aconteceu em 1929, previa, anos depois e a despeito de suas críticas às posições racistas, um país cada vez mais branco: em 2012, teríamos uma população composta de $80 \%$ de brancos e $20 \%$ de mestiços; nenhum negro e nenhum índio (SCHWARCS, 2012, p. 25).

Pelo exposto, reconhecendo que mesmo após a escravidão, o Estado e os seus braços institucionais jurídicos, científicos e educacionais, patrocinaram, durante décadas, a ideologia de higienização do país a fim de alavancar o progresso, não há outra possibilidade de pôr fim ao terror do racismo estrutural atualmente vivenciado no país, senão também, por meio de fomento massivo em políticas públicas orientadas a um novo modelo de organização social, sobretudo que respeite a diversidade.

No entanto, século XXI, na sociedade brasileira, dificilmente observa-se formas explícitas do racismo, aqui compreendido como "características intelectuais e morais de um grupo [sendo] determinadas pelas características físicas e biológicas" (RODRIGUES E AQUINO, 2010, p. 3), o tornando, portanto, um ser superior ou inferior segundo essas características. O que é mais comum, tendo em vista estas novas formas de discriminação é a "exclusão, o esquecimento, o silêncio, a negação, a humilhação".

Isso fica evidente ao ser analisado a representatividade de homens, mulheres e crianças negras na mídia televisiva, espaço no qual estas pessoas também são menosprezadas, subvalorizadas e, em determinadas situações simplesmente invisibilizadas.

No entanto, o movimento negro, combativo desde a década de 1970 no Brasil, foi o responsável por dar vulto e visibilidade nacional a essa triste realidade. Aos poucos, por meio da luta política e do diálogo com um governo comprometido com a pauta de políticas afirmativas, a exemplo do primeiro governo Lula (2003-2006), obtiveram como resultado a promulgação em 2003, da lei 10.639, que estabeleceu a obrigatoriedade do ensino da História e Cultura Africana e Afro Brasileira na escola. Além disso, ainda em 2003, o governo brasileiro instituiu a Seppir (Secretaria Especial de Políticas e Promoção da Igualdade Racial) e a Política Nacional de Promoção da Igualdade Racial, enfatizando a importância em se adotar políticas públicas afirmativas, desencadeando mudanças na realidade vivida da população negra, 
iniciando de maneira sistemática e institucionalizada, um processo de reversão das consequências dos séculos de assassinatos, discriminações e preconceitos. Em 2004, foram estabelecidas as Diretrizes Curriculares Nacionais para a Educação das Relações Etnicorraciais e para o Ensino de História e Cultura Africana e Afro Brasileira (DCNs). A partir dessas ações, portanto, reconheceu-se formalmente que,

O Brasil, Colônia, Império e República, teve historicamente, no aspecto legal, uma postura ativa e permissiva diante da discriminação e do racismo que atinge a população afro-descendente brasileira até hoje. O Decreto $\mathrm{n}^{\circ}$ 1.331, de 17 de fevereiro de 1854, estabelecia que nas escolas públicas do país não seriam admitidos escravos, e a previsão de instrução para adultos negros dependia da disponibilidade de professores. $\mathrm{O}$ Decreto $\mathrm{n}^{\circ}$ 7.031-A, de 6 de setembro de 1878, estabelecia que os negros só podiam estudar no período noturno e diversas estratégias foram montadas no sentido de impedir o acesso pleno dessa população aos bancos escolares (BRASIL, 2004, p. 7).

Neste contexto, não se pode negar que a educação brasileira é reflexo de uma orientação eurocêntrica que acabou conduzindo as pessoas a reproduzirem, consciente ou inconscientemente, as discriminações e preconceitos oriundos da incapacidade, socialmente estabelecida, de lidar com a diversidade humana. Exatamente por isso, a maioria dos livros e outros materiais didáticos refletem em seus conteúdos, os mesmos preconceitos e depreciações a culturas que não possuem a mesma origem ocidental (MUNANGA, 2005, p. 15). Munanga afirma que da mesma maneira como a totalidade das relações sociais estão eivadas destes princípios nos quais as pessoas não são somente classificadas, mas também hierarquizadas tendo como critério suas características morfológicas e cor da pele, as relações na escola, dos estudantes entre si, professores entre si e entre estudantes e os professores, também estão permeadas dos mesmos sentimentos e prejulgamentos. Neste caso, por falta de preparo em lidar com preconceitos introjetados, a escola não consegue aproveitar estes momentos como uma oportunidade pedagógica privilegiada para discutir sobre diversidade, riqueza cultura e identidade nacional.

$\mathrm{Na}$ maioria dos casos, praticam a política de avestruz ou sentem pena dos "coitadinhos", em vez de uma atitude responsável que consistiria, por um lado, em mostrar que a diversidade não constitui um fator de superioridade e inferioridade entre os grupos humanos, mas sim, ao contrário, um fator de complementaridade e de enriquecimento da humanidade em geral; e por outro lado, em ajudar o aluno discriminado para que ele possa assumir com orgulho e dignidade os atributos de sua diferença, sobretudo quando esta foi negativamente introjetada em detrimento de sua própria natureza humana (MUNANGA, 2005, p. 15).

Estas atitudes preconceituosas entre alunos de diferentes ascendências etnicorraciais e sociais, afetam o desempenho com relação ao seu aprendizado, especialmente do aluno negro em relação ao branco, o desestimulando e o tornando mais suscetível a repetência e a evasão (MUNANGA, 2005, p. 16).

Neste contexto, Frantz Fanon e sua obra "Pele Negra, Máscaras Brancas", cuja primeira edição data de 1952, reeditado em 1975 e, finalmente, revisado e editado em 2008 pela Universidade Federal da Bahia, foi e ainda é extremamente importante para a reflexão sobre o racismo na América do Sul, tendo influenciado muitos autores como Paulo Freire, especialmente na pedagogia do oprimido. Fanon nasceu na Ilha da Martinica, se formou em psiquiatria e filosofia na França, e dirigiu o Departamento de Psiquiatria do Hospital Blida-Joinville na Argélia, renomeado como Hospital Frantz Fanon (FANON, 2008, p. 11). 
$\mathrm{Na}$ obra acima citada, Fanon, ao analisar o homem preto e suas psicopatologias, ou seja, o surgimento das neuroses e dos traumas de sua consciência, segundo os fundamentos freudianos, constatou que estas teriam origens em determinadas vivências na infância, em comparação aos fundamentos estabelecidos pela estrutura da família tradicional, branca e burguesa. Afirmou que o homem preto, à medida que entra em contato direto com a realidade social, diante das manifestações subjetivas dos brancos, percebe que muitas das proposições que absorveu, seus ideais e concepções de mundo, são irreais para ele. Este esteve "protegido" enquanto sua existência se desenvolvia apenas entre os seus, antes da escola. A partir do momento em que se insere na escola, o preto entraria em contato com um mito, o ser branco, solidamente enraizado, que inescapavelmente teria que enfrentar. Neste ponto, "[...] ao primeiro olhar branco, ele sente o peso da melanina [...]" (FANON, p. 128 - 133).

É por isso que afirma que,

Fica logo claro que queremos, nem mais nem menos, criar periódicos ilustrados destinados especialmente aos negros, canções para crianças negras, até mesmo livros de história, pelo menos até a conclusão dos estudos. Pois, até prova em contrário, estimamos que, se há traumatismo, ele se situa neste momento da vida (FANON, 2008, p. 132).

Nesse sentido, especialmente no Brasil, a escola e, portanto, todo material de apoio à formação da pessoa e do cidadão, precisa contribuir para que o negro se "reconheça na cultura nacional" expressando uma visão de mundo autônoma, com protagonismo. É preciso que a escola, ao reconhecer, elaborar e compartilhar a história do povo africano e suas referências positivas, contribua para que as crianças negras não se imaginem como seres de segunda classe, inferiores, destinados a terem um papel de subalternidade social. Assim, é preciso considerar um processo de educação que apoie a formação do sujeito que se pensa construtor de sua própria história, que respeita e valoriza a diversidade, constatando que a riqueza cultural de um povo se funda nesta característica.

Portanto, os currículos que tratam do tema transversal sobre pluralidade cultural e educação, precisam deixar de invisibilizar, secundarizar, menosprezar as outras culturas, os outros povos. Persiste, nos livros didáticos, que a representação de toda a humanidade seja expressa pela figura do homem branco, responsável pelo desenvolvimento científico, humano e civilizatório. Às outras matrizes culturais, não são conhecidas em profundidade a fim de que sejam reveladas as contribuições fundamentais oferecidas por elas, à humanidade.

No livro didático a humanidade e a cidadania, na maioria das vezes, são representadas pelo homem branco e de classe média. A mulher, o negro, os povos indígenas, entre outros, são descritos pela cor da pele ou pelo gênero, para registrar sua existência. (SILVA, 2005, p. 21).

A falta de representação positiva de um povo, desencadeia um sentimento de inferiorização e auto rejeição de seus valores estéticos e culturais, prevalecendo os valores dominantes. Por essa razão, se faz necessário construir um caminho pedagógico para se "desmontar estereótipos", no qual os professores, segundo Silva (2005, p. 22), especialmente os que atuam nas séries iniciais, seriam os maiores aliados. O espaço escolar deve promover e "[...] visibilizar as diferentes práticas cotidianas, experiências e processos 
culturais, sem o estigma da desigualdade, colocando todos eles como parte do passado significativo, da tradição e do conhecimento universal [...]".

Pelo exposto, acredita-se que a escola pode atuar como um elemento estrutural de mudança cultural e que, por este motivo, o material didático e toda a literatura que o cerca, especialmente a literatura infantil, deverá reafirmar valores como a igualdade, solidariedade, tolerância, justiça e ética. Nesta perspectiva, Coelho (2000) define a importância da escola

A escola é, hoje, o espaço privilegiado, em que deverão ser lançadas as bases para a formação do indivíduo. E, nesse espaço, privilegiamos os estudos literários, pois, de maneira mais abrangente do que quaisquer outros, eles estimulam o exercício da mente; a percepção do real em suas múltiplas significações; a consciência do eu em relação ao outro; a leitura do mundo em seus vários níveis e, principalmente, dinamizam, o estudo e conhecimento da língua, da expressão verbal significativa e consciente - condição para a plena realidade do ser (COELHO, 2000, p. 16).

Pautado nessa possibilidade de formação do indivíduo que o projeto foi proposto, a fim de estimular as crianças a quererem sonhar e construírem diferentes histórias de vida, indiferente da cor da pele ou situação social que se encontrem.

\section{Considerações sobre os aspectos metodológicos}

Outra dimensão importante do projeto diz respeito as estratégias de aproximação da equipe de trabalho com as crianças do CMEI. Foi necessário um esforço conjunto entre a equipe do projeto e a equipe do CMEI, professoras, diretora, supervisora, para que fosse possível nos envolver no cotidiano da instituição sem causar estranhamento às crianças. Durante os meses de maio e junho de 2017, foram necessárias reuniões com todos os membros, para que conjuntamente fosse definido a melhor maneira de propor as atividades e assim, obter o melhor resultado possível.

Foi decidido, conjuntamente com as professoras das duas turmas do segundo período, em média com vinte e cinco (25) crianças cada, tendo cada uma delas, à época, 5 anos de idade, que os trabalhos seriam desenvolvidos pelas mesmas. Por sugestão de uma das professoras, foi proposto que o bolsista PROCARTE, juntamente com o outro discente colaborador, visitassem as crianças, antes de iniciar o projeto, propondo atividades lúdicas, que envolveram músicas e brincadeiras, a fim de que estas, aos poucos, não mais estranhassem a presença da equipe na escola.

Nesse interim, foi acordado com as professoras das turmas que estas, anteriormente a apresentação da história do livro "Eu posso ser...o que eu quiser ser!" para as crianças, fariam atividades em sala de aula com as mesmas, a partir dos seus planejamentos diários, articulando a temática do livro infantil proposto a algum dos eixos temáticos do conhecimento para a educação infantil: Identidade e autonomia, Matemática, Natureza e sociedade; Música, Movimento, Linguagem Oral e Escrita; Artes Visuais.

Dessa forma, seguindo a lógica de concepção do projeto, as professoras realizaram atividades artísticas, duas semanas antes da apresentação da história da "Princesa Eduarda", nas quais foram possível 
obter das crianças, por meio dos desenhos, qual o seu entendimento e compreensão acerca das relações domésticas, ocupação profissional de seus pais, suas projeções e sonhos infantis, identificando as restrições, problemas e preconceitos que as impediriam de "querer" ou "sonhar" para além do que está posto no seu cotidiano. Nesse caso, os significados dos desenhos foram explicados pelas próprias crianças, que tiveram suas explicações gravadas em áudio.

Importante frisar que esses áudios serviram única e exclusivamente para serem transcritos e anexados aos desenhos, para que a equipe pudesse, posteriormente, avaliar a elaboração de um texto, no caso, o segundo livro, que contemplassem a realidade percebida pelas crianças.

Após essa fase, foi agendado um evento para a contação da história do livro para as crianças, que seguindo a orientação de uma das professoras das turmas, não deveria ser distante do período proposto para as atividades que elas fariam em sala de aula, para que as crianças não se esquecessem de todo processo de discussões realizadas até aquele momento. Assim, com o evento agendado, a equipe realizou a leitura do livro, que foi projetado na sala de refeições, como já dito anteriormente, e logo após a leitura e discussão, as crianças foram estimuladas a desenharem uma história sobre o que gostariam de ser quando crescer. De acordo com Cosson (2014)

Os que se prendem aos programas curriculares escritos a partir da história da literatura precisam vencer uma noção conteudista do ensino para compreender que, mais que um conhecimento literário, o que se pode trazer ao aluno é uma experiência de leitura a ser compartilhada (COSSON, 2014, p. 23).

A valorização da participação dos alunos aconteceu de forma envolvente por toda a equipe do projeto. Os alunos foram desenhando e cada rabisco ou desenho podiam explicar o que queriam dizer. Foram momentos muito produtivos, trazendo aos alunos "uma experiência de leitura compartilhada". Mais uma vez, as explicações dos desenhos foram gravadas em áudio que, posteriormente, foram anexadas a cada desenho correspondente.

Após essas duas etapas, foram realizadas análises com os trabalhos das crianças, antes e depois da história contada pela equipe do projeto. A coordenadora do projeto com o apoio do bolsista, e com o discente colaborador, organizaram, de acordo com a avaliação da equipe, a história contada por estas crianças em outro livro, o "Clube da alegria", cujo texto foi elaborado pela coordenadora do projeto. Importante ressaltar, que um membro da equipe, à época mestranda em Educação, propôs que musicalizássemos a história do primeiro livro, como forma de aumentar a sensibilização das crianças com relação a história da "Princesa da Alegria". Ela se prontificou a fazer a letra com uma melodia conhecida, já que, segundo sua experiência, uma melodia conhecida facilitaria a memorização da letra pelas crianças. Assim foi feito. As crianças aprenderam a letra e cantaram:

\footnotetext{
"A pequena Eduarda,

Vivia triste a perguntar,

Porque nos livros não existiam

Princesas negras, porque será?

A princesa da alegria

Decidiu sua história contar,

Então crianças, nesse momento
} 
Um novo mundo vamos pintar!

Uma história colorida,

Vamos todos imaginar,

A cada página do novo livro,

Todas crianças vão poder se encontrar."

A música, em ritmo de "Fui morar numa casinha", foi acompanhada no violão por um dos integrantes do projeto. Importante considerar que a equipe da escola apostou no projeto, e na capacidade deste gerar autoestima entre as crianças, e também, na própria equipe. Em uma das reuniões com os profissionais da escola, foram realizadas, pelas mesmas, várias análises pontuais sobre a realidade das crianças, e de como a proposta desse projeto se justifica, à medida que se preocupa com a formação dos pequenos desde a base. Segundo o relato de uma das professoras, é muito difícil mudar o ponto de vista ou concepções de mundo dos adolescentes. Nas escolas de ensino fundamental em que lecionou, os adolescentes vivem uma realidade social difícil, pobre, com desagregação familiar, muitas vezes presenciando violência doméstica. Além disso, contam com o fato de que, dificilmente serão reprovados na escola, o que os fazem, segundo sua visão, optar pela lei do menor esforço. "É muito difícil estimular estes estudantes a quererem mais do que aquilo que já está estabelecido nas suas vidas". A luta somente do professor, em sala de aula, ou mesmo da escola, passa a ser inócua. O importante é iniciar da base, na educação infantil, e esse projeto estaria estimulando exatamente isso. Foram várias as colocações nesse sentido, o que gerou uma expectativa e engajamento positivo pelo bom resultado do projeto.

\section{Considerações Finais}

São muitos os desafios para a realização de um projeto de extensão universitária, de acordo com o fundamento do conceito extensionista. Significa que é necessário que a universidade não se reconheça como detentora absoluta do conhecimento científico produzido e acumulado, e esteja disposta a reconhecer e valorizar os conhecimentos e saberes produzidos pela comunidade externa e pelos seus profissionais. Nesse sentido, as parcerias entre instituições, obtidas por meio dos projetos de extensão, necessitam estabelecer interações dialógicas, que priorizem relações horizontais entre os participantes, que necessitam estar abertos a trocas frequentes de experiências, o que enriquece sobremaneira qualquer atividade proposta.

Para tanto, essas relações se iniciam e necessitam ser estabelecidas antes da execução do projeto propriamente dito, pois lidam com a vida das pessoas, expectativas, medos, angústias e esperanças. Não há dúvidas de que a extensão universitária é, de fato, quando bem executada, um caminho promissor para democratização dos saberes e desenvolvimento local e regional. 
Sendo assim, se faz necessário manter investimentos públicos constantes que viabilizem bolsas de extensão, deslocamentos, compras de equipamentos e outros recursos fundamentais ao bom andamento do projeto e a manutenção deste.

Neste projeto em questão, as crianças estavam completamente à vontade com os extensionistas, viabilizando o contato individual com elas, por vezes, sem a presença das professoras, que permaneceram nas salas de aula com outras crianças. No decorrer do projeto, para que fosse possível atingir o objetivo de elaborar uma história contada pelas próprias crianças, foi identificado a necessidade de ir além da contação da história do primeiro livro, pois algumas delas ainda estavam muito acanhadas e falaram muito pouco, e precisavam de mais estímulos para falar. Sendo assim, a música, e outras atividades lúdicas propostas por meio de uma parceria com professores do curso de Licenciatura da Educação Física da UFVJM, proporcionou intensidade e maior ludicidade na interação.

Outro ponto importante a ser reiterado, diz respeito ao investimento governamental com relação as políticas públicas orientadas a valorização das outras matrizes culturais brasileiras, notadamente as africanas e indígenas. Não será possível vencer o racismo estrutural brasileiro sem que o Estado e seus braços institucionais, provoquem e impulsionem essa mudança para o bem de toda a nação.

\section{Referências}

BRASIL. Diretrizes curriculares nacionais para a Educação das Relações Étnico-Raciais e para o Ensino de História e Cultura Afro-Brasileira e Africana. Conselho Nacional de Educação/Conselho Pleno. Brasília: 2004.

COELHO, Nelly Novaes. Literatura infantil: teoria, análise, didática. São Paulo: Moderna, 2000.

COSSON, Rildo. Círculos de leitura e letramento literário. São Paulo: Contexto, 2014.

FANON, Frantz. Pele Negra Máscaras Brancas. Salvador: ADUFBA, 2008.

FÓRUM DE PRÓ-REITORES DE EXTENSÃO DAS UNIVERSIDADE PÚBLICAS BRASILEIRAS BRASIL. O Plano Nacional de Extensão Universitária. (Coleção Extensão Universitária;vol.1) Disponível em: <https://www.ufmg.br/proex/renex/documentos/Colecao-Extensao-Universitaria/01Plano-Nacional-Extensao/Plano-nacional-de-extensa HYPERLINK "https://www.ufmg.br/proex/renex/documentos/Colecao-Extensao-Universitaria/01-Plano-NacionalExtensao/Plano-nacional-de-extensao-universitaria-editado.pdf"o-universitaria-editado.pdf.> Acessado em: 05/08/2016. 
MUNANGA, Kabengele (Org.). Apresentação. In: MUNANGA, Kabengele. Superando o racismo na escola. $2^{\circ}$ Ed. revisada. Brasília: Ministério da Educação, Secretaria de Educação Continuada, Alfabetização e Diversidade. 2005 p.15-20.

ROGRIGUES, Poliana Resende Soares; AQUINO, Miriam de Albuquerque. A (in)visibilidade da pessoa negra na literatura infantil: (Im)possibilidades de afirmação da identidade afrodescendente na escola. III Seminário Nacional de Estudos Culturais Afro-Brasileiros: literatura, negritude e política. Cadernos Imbondeiro: João Pessoa. vol.1, n.1. 2010, ISSN 2316-2937.

SCHWARCZ, Lilia Moritz. O Espetáculo das Raças: Cientistas, Instituições e Questão Racial no Brasil 1870 - 1930. São Paulo: Companhia das Letras, 1993.

SCHWARCZ, Lilia Moritz. Nem Preto Nem Branco, Muito Pelo Contrário: Cor e raça na sociabilidade brasileira. São Paulo: Claro Enigma, 2012.

SILVA, Ana Celia da. A Desconstrução da Discriminação no Livro Didático. In: MUNANGA, Kabengele (Org.). Superando o racismo na escola. $2^{\circ}$ Ed. revisada. Brasillia: Ministério da Educação, Secretaria de Educação Continuada, Alfabetização e Diversidade. 2005 p.21-38.

ZILBERMAN, Regina. O Papel Da Literatura Na Escola, Via Atlântica. São Paulo. jun. 2009, s/v. n 14, $12-22$. 